\title{
Benefits of pulmonary rehabilitation in COVID-19: a prospective observational cohort study
}

\author{
Rainer Gloeckl ${ }^{1,2,7}$, Daniela Leitl ${ }^{1,2,7}$, Inga Jarosch ${ }^{1,2}$, Tessa Schneeberger ${ }^{1,2}$, \\ Christoph Nell ${ }^{3}$, Nikola Stenzel ${ }^{4}$, Claus F. Vogelmeier ${ }^{5}$, Klaus Kenn ${ }^{1,2}$ and \\ Andreas R. Koczulla ${ }^{1,2,6}$
}

Affiliations: ${ }^{1}$ Dept of Pulmonary Rehabilitation, Philipps-University of Marburg, Member of the German Center for Lung Research (DZL), Marburg, Germany. ${ }^{2}$ Institute for Pulmonary Rehabilitation Research, Schoen Klinik Berchtesgadener Land, Schoenau am Koenigssee, Germany. ${ }^{3}$ Dept of Pulmonology, Philipps-University Marburg, Marburg, Germany. ${ }^{4}$ Psychologische Hochschule Berlin (PHB), Berlin, Germany. ${ }^{5}$ Dept of Medicine, Pulmonary and Critical Care Medicine, University Medical Centre Giessen and Marburg. Philipps-University of Marburg, Member of the DZL, Marburg, Germany. ${ }^{6}$ Teaching Hospital, Paracelsus Medical University, Salzburg, Austria. ${ }^{7}$ These authors contributed equally.

Correspondence: Rainer Gloeckl, Institute for Pulmonary Rehabilitation Research, Schoen Klinik Berchtesgadener Land, Malterhoeh 1, 83471 Schoenau am Koenigssee, Germany. E-mail: RGloecklaSchoen-Klinik.de

\section{ABSTRACT}

Background: Coronavirus disease 2019 (COVID-19) can result in a large variety of chronic health issues such as impaired lung function, reduced exercise performance and diminished quality of life. Our study aimed to investigate the efficacy, feasibility and safety of pulmonary rehabilitation in COVID-19 patients and to compare outcomes between patients with a mild/moderate and a severe/critical course of the disease. Methods: Patients in the post-acute phase of a mild to critical course of COVID-19 admitted to a comprehensive 3-week inpatient pulmonary rehabilitation programme were included in this prospective, observational cohort study. Several measures of exercise performance (6-min walk distance (6MWD)), lung function (forced vital capacity (FVC)) and quality of life (36-question short-form health survey (SF-36)) were assessed before and after pulmonary rehabilitation.

Results: 50 patients were included in the study (24 with mild/moderate and 26 with severe/critical COVID19). On admission, patients had a reduced 6MWD (mild: median $509 \mathrm{~m}$, interquartile range (IQR) $426-$ 539 m; severe: $344 \mathrm{~m}, 244-392 \mathrm{~m}$ ), an impaired FVC (mild: 80\%, 59-91\%; severe: 75\%, 60-91\%) and a low SF-36 mental health score (mild: 49 points, $37-54$ points; severe: 39 points, $30-53$ points). Patients attended a median (IQR) 100\% (94-100\%) of all provided pulmonary rehabilitation sessions. At discharge, patients in both subgroups improved in 6MWD (mild/moderate: $+48 \mathrm{~m}, 35-113 \mathrm{~m}$; severe/critical: $+124 \mathrm{~m}$, 75-145 m; both $\mathrm{p}<0.001$ ), FVC (mild/moderate: $+7.7 \%, 1.0-17.8 \%, \mathrm{p}=0.002$; severe/critical: $+11.3 \%$, $1.0-16.9 \%, \mathrm{p}<0.001$ ) and SF-36 mental component (mild/moderate: +5.6 points, $1.4-9.2$ points, $\mathrm{p}=0.071$; severe/critical: +14.4 points, $-0.6-24.5, \mathrm{p}<0.001)$. No adverse event was observed.

Conclusion: Our study shows that pulmonary rehabilitation is a feasible, safe and effective therapeutic option in COVID-19 patients independent of disease severity.

@ERSpublications

Pulmonary rehabilitation is effective, feasible and safe to improve exercise performance, lung function and quality of life in patients with persistent impairments due to a mild to critical course of \#COVID19 https://bit.ly/3kQFIbs

Cite this article as: Gloeckl R, Leitl D, Jarosch I, et al. Benefits of pulmonary rehabilitation in COVID-19: a prospective observational cohort study. ERJ Open Res 2021; 7: 00108-2021 [https:// doi.org/10.1183/23120541.00108-2021].

This article has supplementary material available from openres.ersjournals.com

This study is registered at www.clinicaltrials.gov with identifier number NCT04649918.

Data availability: A pseudonymised dataset will be made available upon reasonable request to the corresponding author. The request must include a statistical analysis plan.

Received: 12 Feb 2021 | Accepted: 23 Feb 2021

Copyright $\odot$ The authors 2021. This version is distributed under the terms of the Creative Commons Attribution NonCommercial Licence 4.0. For commercial reproduction rights and permissions contact permissions@ersnet.org 


\section{Background}

Disease severity in coronavirus disease 2019 (COVID-19) can be very heterogeneous. 40\% of COVID-19 subjects develop mild disease (defined as symptomatic patients without evidence of viral pneumonia or hypoxia); another $40 \%$ have a moderate disease (with clinical signs of pneumonia); $15 \%$ suffer from a severe disease (with severe pneumonia) that requires oxygen therapy; and 5\% develop a critical disease with complications such as respiratory failure, acute respiratory distress syndrome, thromboembolism, sepsis and/or multiorgan failure [1,2]. Older age, smoking and pre-existing comorbidities have been reported to be risk factors for a more severe course of COVID-19 and an increased mortality [3, 4].

Even 2-3 months after being "cured" of the severe acute respiratory syndrome coronavirus 2 (SARS-CoV-2) infection, many patients are still affected with chronic, clinically relevant sequelae. Frequently reported health issues are a new illness-related fatigue (53-87\%), breathlessness (43-71\%) or neuropsychological impairments (47\%), with a high prevalence of psychological disorders such as increased levels of stress, anxiety and depression [5-8]. According to recent National Institute for Health and Care Excellence guidelines, signs and symptoms of COVID-19 from 4 to 12 weeks after the onset of first symptoms are defined as "ongoing symptomatic COVID-19" [9], whereas COVID-19 sequelae that last $>12$ weeks are summarised by terms such as "long-COVID" or "post-COVID-19 syndrome" [9, 10] The latter are typically more pronounced in patients that needed treatment on an intensive care unit (ICU) compared to ward patients [5].

Based on the individual deficits in COVID-19 patients, comprehensive and multidisciplinary rehabilitation such as pulmonary rehabilitation should be offered with attention to improving respiratory, physical and psychological impairments, as suggested by various international expert groups [11-13]. CARDA et al. [14] suggested providing pulmonary rehabilitation treatment based on the content that is usually recommended in lung fibrosis, since COVID-19 can also induce a restrictive lung disease.

So far, only few retrospective data and case series on pulmonary rehabilitation in COVID-19 have been published. Therefore, the aim of our study was to prospectively investigate the efficacy, feasibility and safety of pulmonary rehabilitation in COVID-19 patients and to compare differences in pulmonary rehabilitation outcomes between patients with a mild/moderate and a severe/critical course of the disease.

\section{Methods}

\section{Study design}

COVID-19 patients with persistent impairments following their SARS-CoV-2 infection were referred to pulmonary rehabilitation by the hospital (severe/critical COVID-19) or by their general practitioner (mild/ moderate COVID-19). Patients admitted to a comprehensive, inpatient pulmonary rehabilitation programme at the Schoen Klinik Berchtesgadener Land (Schoenau am Koenigssee, Germany) were screened for eligibility to participate in this prospective, observational cohort study. Patients were recruited between November 2020 and January 2021. This study was submitted to the clinical trials registry www.clinicaltrials.gov (identifier number NCT04649918) and approved by the ethics committee of the Philipps-University of Marburg (approval number: 85/20). This manuscript was written according to the Strengthening the Reporting of Observational Studies in Epidemiology guideline.

\section{Study population}

Inclusion criteria were patients 1) in the post-acute phase of mild, moderate, severe or critical COVID-19 as defined by the World Health Organization [2]; and 2) providing written informed consent. Patients unable to walk were excluded from the study.

\section{Intervention}

Patients participated in a 3-week comprehensive multimodal and multidisciplinary inpatient pulmonary rehabilitation. The pulmonary rehabilitation programme for COVID-19 patients was based on the pulmonary rehabilitation content for patients with lung fibrosis (as suggested by CARDA et al. [14]) and is described in detail in table 1.

\section{Outcomes and measures}

Exercise performance

6-min walk distance (6MWD) was the primary outcome of this study. One 6-min walk test was performed on admission and one at discharge from pulmonary rehabilitation [15]. $30 \mathrm{~m}$ is regarded as the threshold of the minimal important difference (MID) [15].

Additionally, the following comprehensive exercise testing was performed in the subgroup of patients with severe/critical COVID-19 only, to assess the complexity of severe/critical COVID-19 in more detail. 
An endurance shuttle walk test (ESWT) was performed at $85 \%$ of the maximum walking speed derived from an incremental shuttle walk test [15]. Both tests were performed on the day following the 6-min walk test. Physiological parameters such as oxygen saturation and heart rate were measured continuously using a Sentec Digital Monitor (SenTec, Therwil, Switzerland). Breathing frequency was assessed using an Apnea Link device (ResMed, Martinsried, Germany). To compare physiological changes after pulmonary rehabilitation at an equal level of exercise performance, these outcomes were analysed at baseline and ESWT isotime (end of the shortest ESWT).

Maximum isometric knee extension force at $90^{\circ}$ knee angle (MicroFET 2 dynamometer) and handgrip force (JAMAR hand dynamometer) were assessed by dynamometry using the best out of three tests [16]. A five-repetition sit-to-stand test was performed from a 46-cm-high chair with arms crossed in front of the chest [17] and the frailty phenotype was assessed using the Fried frailty index [18].

\section{Respiratory parameters}

Body plethysmography was performed in all patients to measure forced vital capacity (FVC), forced expiratory volume in $1 \mathrm{~s}\left(\mathrm{FEV}_{1}\right)$, total lung capacity and diffusing capacity of the lung for carbon monoxide. Capillary blood gas samples to assess the partial oxygen pressure and partial carbon dioxide pressure were taken at rest, breathing ambient air.

\section{TABLE 1 Description of the standardised pulmonary rehabilitation programme in coronavirus} disease 2019 (COVID-19)

\section{Diagnostics and medical treatment}

Endurance training

Strength training

Patient education

Respiratory physiotherapy

Activities of daily living training

Relaxation techniques

Occupational therapy

Psychological support

Nutritional counselling
Initial physical check-up including body plethysmography, electrocardiography, cardiac ultrasound, blood sampling Continuous adaptation of drug treatment

Initiation and adjusting of long-term oxygen therapy, if necessary

If necessary, patients received a high-resolution chest computed tomography, sleep lab diagnostics or an online consultation with a neurologist

Cycle endurance training was performed for 10-20 min per session at $60-70 \%$ of peak work rate 5 days per week

Strength training was performed using resistance training machines The following exercises were performed: leg press, knee extension, pull-down and push-down

If possible, the following additional exercises were applied: butterfly forward/backward, rowing, back extension and abdominal trainer

Patients performed three sets per exercise at an individual intensity to reach momentary muscular failure after $15-20$ repetitions

Resistance training usually took $\sim 30$ min per session and was applied 5 days per week

Patients visited two educational sessions per week about COVID-19 as well as on general topics such as physical activity, oxygen therapy and smoking cessation

Individually tailored chest physiotherapy using various techniques such as breathing retraining, cough techniques, mucus clearance, connective tissue massage, energy conservation techniques, etc. was applied two to four times per week for 30 min each

Activities of daily living training (calisthenics) was applied four to five times per week for $30 \mathrm{~min}$

In addition, Nordic walking or aqua fitness were applied twice per week for $30 \mathrm{~min}$

QiGong or progressive muscle relaxation ( Jacobson technique) were applied twice per week for $30 \mathrm{~min}$

Occupational therapy was used to treat individual neurological issues such as limited motor ability in the hands or insecure gait (if needed)

Brain-performance training was performed to improve memory and concentration

A psychologist supported COVID-19 patients individually as well as during group therapy on aspects of disease management and coping with COVID-19 and its sequelae

If necessary, nutritional counselling or nutritional supplements were provided to recover body composition lafter body weight loss during hospital stayl 
The subjective effect of breathlessness on daily activities was assessed using the modified Medical Research Council dyspnoea scale [19].

\section{Quality of life, psychological distress and (cognitive) impairment}

Generic quality of life was assessed using the physical and mental components sum score of the short-form 36-question health survey (SF-36). The score ranges from 0 to 100, with higher scores indicating better quality of life.

Anxiety symptoms were assessed using the Generalized Anxiety Disorder-7 (GAD-7) questionnaire. GAD-7 scores are interpreted as follows: no anxiety symptoms (0-4 points), mild symptoms (5-9 points), moderate symptoms (10-14 points) and severe symptoms (15-21 points) [20].

Depressive symptomatology was assessed using the nine-item depression scale of the Patient Health Questionnaire (PHQ-9). PHQ-9 scores are interpreted as follows: no depressive symptomatology (0 points), minimal symptoms of depression (1-4 points), mild symptoms of depression (5-9 points), moderate symptoms of depression (10-14 points) and severe symptoms of depression (15-27 points) [21].

The Montreal Cognitive Assessment is a widely used screening assessment for detecting cognitive impairment ( $<26$ out of a maximum of 30 points) [22].

\section{Sample size}

Due to a lack of data we did not perform an a priori sample size calculation. However, a post hoc power calculation based on the mean and standard deviation of the improvements in the primary outcome (6MWD) showed an effect size of 1.21 for the group of 24 mild/moderate COVID-19 patients and an effect size of 1.75 for the severe/critical COVID-19 group to analyse the changes in exercise performance.

\section{Statistical methods}

Results are presented as median (interquartile range). Nonparametric tests have been used for statistical analyses due to the small sample size. For comparing pre- to post-pulmonary rehabilitation effects within the two groups, a two-tailed Wilcoxon rank-sum test or Chi-squared test was applied, as appropriate. The Mann-Whitney U-test was used to compare between-group differences and the Kruskal-Wallis test including a post hoc U-test with Bonferroni correction was applied to compare results between three groups (data are shown in the supplementary material). The McNemar test was used to analyse categorical data. The significance level was set at $\mathrm{p}<0.05$. Statistical analyses were performed using SPSS 26 (IBM, Armonk, NY, USA).

\section{Results}

50 out of 58 eligible patients were included in the study. Eight patients were excluded due to the following reasons: three were too weak to perform a walk test, one refused to participate, one had language difficulties, one was isolated due to a multiresistant infection and two had other reasons.

\section{Baseline characteristics}

24 patients had a mild/moderate course of COVID-19 which was treated in an outpatient setting and 26 had severe/critical COVID-19 and were hospitalised for a median (IQR) 37 (18-60) days (table 2). 85\% of these severe/critical COVID-19 patients were treated on an ICU for 28 (15-40) days and 58\% needed mechanical ventilation for 18 (11-43) days.

Upon admission to pulmonary rehabilitation, patients with severe/critical COVID-19 had significantly lower exercise performance (6MWD $344 \mathrm{~m}$ versus $509 \mathrm{~m} ; \mathrm{p}<0.001$ ) and worse lung function (FVC 75.1\% versus $80.0 \%$; $\mathrm{p}<0.004)$ compared to patients with mild/moderate COVID-19. Quality of life as assessed using SF-36 was reduced to a similar level in all outcomes in both subgroups (table 3 ).

\section{Pulmonary rehabilitation outcomes}

Post-COVID-19 patients attended a median (IQR) 100\% (94-100\%) of all provided pulmonary rehabilitation sessions. At pulmonary rehabilitation discharge, patients in both subgroups were able to improve exercise performance significantly by $48 \mathrm{~m}$ (mild/moderate COVID-19: $88 \%$ of patients exceeded the MID, $\mathrm{p}=0.001$ ) and $124 \mathrm{~m}$ (severe/critical COVID-19: $92 \%$ of patients exceeded the MID, $\mathrm{p}<0.001$ ), respectively (figure 1). Additionally, measures of lung function such as FVC or FEV $\mathrm{F}_{1}$ improved significantly in the range $7.7-15.7 \%$ within both groups (see details in table 3). Quality of life improved significantly only in patients with severe/critical COVID-19 in the mental component sum score of the SF-36 (from 38.5 to 52.9 points; $\mathrm{p}<0.001$ ). 
Furthermore, in the group of severe/critical COVID-19 patients, there was a significant improvement in frailty status (table 4). ESWT duration improved from $460 \mathrm{~s}$ to $1200 \mathrm{~s}(\mathrm{p}=0.001)$ with 14 (54\%) patients reaching the test duration maximum of $20 \mathrm{~min}$. In addition, severe desaturations (oxygen saturation $<85 \%$ ) during ESWT were significantly less common at pulmonary rehabilitation discharge (five versus one patient; $\mathrm{p}<0.001)$ and breathing frequency at isotime reduced from 50 to 45 breaths $\mathrm{min}^{-1}(\mathrm{p}=0.005)$ (table 4). No adverse event was observed during the pulmonary rehabilitation period. However, patients with severe/critical COVID-19 reported persistent COVID-19-related impairments at pulmonary rehabilitation discharge for symptoms such as dyspnoea (73\%), fatigue (58\%) or cough (35\%) (supplementary figure S3).

\section{Discussion}

Our study shows that pulmonary rehabilitation is feasible (with a very high adherence rate of pulmonary rehabilitation sessions), safe (no adverse events) and beneficial to improve exercise performance, lung function and quality of life in patients with persistent sequelae due to a mild to critical course of COVID-19. To the best of our knowledge, this is the first prospective study investigating the effects of a comprehensive pulmonary rehabilitation in post-acute COVID-19 patients. In a recent systematic review, NEGRIN et al. [23] determined the level of evidence of pulmonary rehabilitation in COVID-19 patients to be low. Searching the PubMed library with the terms "pulmonary rehabilitation" and "COVID-19" on 7 February 2021 yielded only four studies that have investigated the effects of pulmonary rehabilitation in COVID-19 patients so far. Two studies were case series reports describing seven [24] and three [25] cases of COVID-19 pulmonary rehabilitation. One study was conducted as a randomised controlled trial in 72 patients with a severe acute course of COVID-19 [26]. However, this study provided home-based respiratory muscle training as the main content and should therefore not be considered as pulmonary rehabilitation, which is defined as a much more comprehensive intervention according to the current American Thoracic Society/European Respiratory Society pulmonary rehabilitation statement [27]. Only Hermann et al. [28] investigated the effects of a comprehensive inpatient pulmonary rehabilitation programme similar to ours by retrospectively analysing data from 28 patients with severe/critical

\section{TABLE 2 Baseline characteristics}

Mild/moderate COVID-19 Severe/critical CoVID-19

$\begin{array}{lcc}\text { Subjects } & 24 & 26 \\ \text { Age years } & 52(47-56) & 66(60-71) \\ \text { Female } & 20(83) & 8(31) \\ \text { BMI } \mathbf{~ g g} \cdot \mathbf{m}^{-2} & 24.7(22.0-29.8) & 26.9(24.2-29.2) \\ \text { Smoking status current/former/never/unknown } & 2 / 5 / 10 / 7 & 1 / 19 / 6 / 0 \\ \text { Hospitalisation } & 0(0) & 26(100) \\ \text { Duration of hospitalisation days } & N A & 37(18-60) \\ \text { ICU stay } & 0(0) & 22(85) \\ \text { Duration of ICU stay days } & N A & 28(15-40) \\ \text { Oxygen therapy during hospitalisation } & 0(0) & 24(92) \\ \text { Mechanical ventilation during ICU stay } & 0(0) & 15(58) \\ \text { Duration of mechanical ventilation days } & N A & 18(11-43) \\ \text { Duration between first positive PCR test and } & 178(127-217) & 61(40-108) \\ \text { admission to pulmonary rehabilitation days } & & \\ \text { Duration between hospital discharge and } & N A & 18(5-40) \\ \text { admission to pulmonary rehabilitation days } & & 3(3-5) \\ \text { Comorbidities prior to CoVID-19 } & 2(2-4) & 16(62) \\ \text { Arterial hypertension } & 5(21) & 10(38) \\ \text { Dyslipidaemia } & 3(13) & 7(27) \\ \text { Coronary heart disease } & 1(5) & 6(23) \\ \text { Diabetes mellitus } & 1(5) & 5(19) \\ \text { Chronic lung disease } & 7(30) & 9(35) \\ \text { Obstructive sleep apnoea } & 9(38) & 6(23) \\ \text { Chronic kidney disease } & 0(0) & 5(19) \\ \text { Obesity } & 5(21) & 1(4) \\ \text { Stroke } & 0(0) & \end{array}$

Data are presented as n, median (interquartile range) or median (\%). COVID-19: coronavirus disease 2019; BMI: body mass index; ICU: intensive care unit; NA: not applicable. 
TABLE 3 Outcomes of a comprehensive inpatient pulmonary rehabilitation (PR) in 50 post-acute coronavirus disease 2019 (COVID-19) patients

\begin{tabular}{|c|c|c|c|c|c|c|c|}
\hline & \multicolumn{3}{|c|}{ Mild/moderate COVID-19 } & \multicolumn{3}{|c|}{ Severe/critical COVID-19 } & \multirow{2}{*}{$\begin{array}{l}\text { Between-group } \\
\text { difference } p \text {-value }\end{array}$} \\
\hline & Pre-PR & Post-PR & Change & Pre-PR & Post-PR & Change & \\
\hline Subjects & & 24 & & & 26 & & \\
\hline \multicolumn{8}{|l|}{ Exercise performance } \\
\hline 6MWD m & $509(426-539)$ & $557(463-633)$ & $48^{* * *}(35-113)$ & 344 (244-392) & $468(374-518)$ & $124^{* * *}(75-145)$ & 0.009 \\
\hline 6MWD \% pred & $70.1(57.8-80.2)$ & $81.0(67.9-90.7)$ & $10.9 * * *(4.7-14.6)$ & $52.5(42.4-58.3)$ & $70.5(59.5-82.6)$ & $18.0 * * *(11.2-23.1)$ & 0.002 \\
\hline $6 \mathrm{MWT} \mathrm{S}_{\mathrm{pO}_{2}}$ nadir $\%$ & $95.5(94.0-97.0)$ & $95.5(93.0-97.0)$ & $0.0(-2.0-1.0)$ & $92.0(87.8-94.2)$ & $93.0(85.5-94.5)$ & $1.0(-1.0-2.5)$ & 0.19 \\
\hline End-6MWT dyspnoea Borg scale & $4(3-5)$ & $4(2-6)$ & $0(-1-1)$ & $5(4-6)$ & $5(3-6)$ & $0(-2-1)$ & 0.83 \\
\hline \multicolumn{8}{|l|}{ General } \\
\hline Oxygen therapy at rest & $0(0)$ & $0(0)$ & 0 & $5(19)$ & $3(11)$ & $-2 * * *(-7)$ & 0.16 \\
\hline Oxygen therapy during exertion & $0(0)$ & $0(0)$ & 0 & $8(31)$ & $7(27)$ & $-1 * * *(-4)$ & 0.33 \\
\hline \multicolumn{8}{|l|}{ Respiratory parameters } \\
\hline $\begin{array}{l}P_{\mathrm{aO}_{2}} \mathrm{mmHg} \text { lat rest and } \\
\text { ambient air) }\end{array}$ & $73.1(63.6-77.4)$ & $75.8(71.0-80.2)$ & $2.7^{*}(-0.9-10.8)$ & $73.2(62.7-77.6)$ & $75.7(71.0-80.2)$ & $2.5^{*}(-1.2-10.5)$ & 0.95 \\
\hline $\begin{array}{l}P_{\mathrm{aCO}_{2}} \mathrm{mmHg} \text { lat rest and } \\
\text { ambient air) }\end{array}$ & $35.0(32.6-38.5)$ & $34.8(31.1-36.5)$ & $-1.2(-2.7-2.5)$ & $35.5(31.8-36.9)$ & $35.3(31.8-36.9)$ & $-0.2(-2.9-2.7)$ & 1.00 \\
\hline$D_{\mathrm{Lco}} \%$ pred & $57.0(50.0-65.5)$ & $61.5(50.0-76.3)$ & $4.5(-1.8-16.5)$ & $55.8(37.2-63.0)$ & $59.5(37.8-70.9)$ & $3.7^{* * *}(-0.5-12.7)$ & 0.92 \\
\hline$K_{\text {Co }} \%$ pred & $67.6(41.5-91.1)$ & $77.9(55.6-95.1)$ & $10.3(-3.0-11.8)$ & $85.0(81.5-99.5)$ & $89.0(80.0-102.5)$ & $4.0(-4.5-9.5)$ & 0.38 \\
\hline TLC \% pred & $82.2(65.3-88.9)$ & $81.1(69.3-95.1)$ & $-1.1(-4.7-10.7)$ & $80.9(64.4-88.6)$ & $81.0(68.8-93.3)$ & $0.1(-4.3-10.5)$ & 0.91 \\
\hline FVC \% pred & $80.0(59.2-90.9)$ & $87.7(67.0-98.9)$ & $7.7^{* *}(1.0-17.8)$ & $75.1(59.8-90.6)$ & $86.4(67.6-96.3)$ & $11.3^{* * *}(1.0-16.9)$ & 0.97 \\
\hline $\mathrm{FEV}_{1} \%$ pred & $83.3(65.5-101.1)$ & $95.1(84.0-106.8)$ & $11.8^{* * *}(3.3-18.1)$ & $79.1(65.8-99.7)$ & $94.8(80.9-106.2)$ & $15.7^{* * *}(3.7-17.5)$ & 0.95 \\
\hline \multicolumn{8}{|l|}{ Quality of life } \\
\hline SF-36 physical component sum score & $31.8(26.2-35.7)$ & $31.7(31.7-42.0)$ & $-0.1(-4.0-9.9)$ & $30.2(22.7-36.8)$ & $34.7(30.2-41.3)$ & $4.5(0.5-9.5)$ & 0.59 \\
\hline SF-36 mental component sum score & $48.6(37.2-53.8)$ & $54.2(52.5-56.7)$ & $5.6(1.4-9.2)$ & $38.5(30.1-52.8)$ & $52.9(32.0-58.2)$ & $14.4^{* * *}(-0.6-24.5)$ & 0.036 \\
\hline \multicolumn{8}{|l|}{ Laboratory parameters } \\
\hline CRP $\mathrm{mg} \cdot \mathrm{L}^{-1}$ & $1.4(0.6-3.9)$ & $1.0(0.6-2.2)$ & $-0.4(-1.2-0.1)$ & $2.6(1.5-5.4)$ & $2.0(1.3-3.9)$ & $-0.6(-1.6-0.4)$ & 0.95 \\
\hline Leukocytes $\mathrm{g} \cdot \mathrm{L}^{-1}$ & $5.9(5.3-6.4)$ & $5.6(4.9-6.3)$ & $-0.3(-1.1-0.1)$ & $7.2(6.0-9.7)$ & $7.0(6.0-9.7)$ & $-0.2(-0.8-1.1)$ & 0.19 \\
\hline $\mathrm{D}$-dimer $\mu \mathrm{g} \cdot \mathrm{mL}^{-1}$ & 292 (196-498) & $291(210-537)$ & $-1(-25-30)$ & 726 (367-982) & 428 (307-807) & $-298 * * *(-639-14)$ & 0.001 \\
\hline Pro-BNP $\mathrm{pg} \cdot \mathrm{mL}^{-1}$ & $72(56-106)$ & $56(33-91)$ & $-16 *(-28-7)$ & 130 (59-335) & $147(74-361)$ & $17(-91-39)$ & 0.44 \\
\hline $\begin{array}{l}\text { Data are presented as } \mathrm{n} \text {, median linterq } \\
\text { pressure; } P_{\mathrm{aco}}: \text { partial carbon dioxide } \\
\text { capacity; } \mathrm{FVC} \text { : forced vital capacity; } \mathrm{FEV} \\
\text { from pre- to post-PR; }{ }^{* *}: \mathrm{p}<0.01 \text { from } \mathrm{pr}\end{array}$ & $\begin{array}{l}\text { ile range) or } \mathrm{n}(\% \\
\text { ssure; } D_{\mathrm{Lco}} \text { : diffu } \\
\text { rced expiratory vc }\end{array}$ & 1, unless otherwise & $\begin{array}{l}\text { stated. 6MWD: } 6-\mathrm{m} \\
\text { lung for carbon } n \\
36 \text {-question short- }\end{array}$ & $\begin{array}{l}\text { walk distance; } \\
\text { loxide; } K_{\mathrm{co}} \text { : tra } \\
\mathrm{m} \text { health surve }\end{array}$ & WT: 6-min walk $\mathrm{t}$ & $\begin{array}{l}S_{\mathrm{pO}_{2}}: \text { oxygen satur } \\
\text { lung for carbon } \eta \\
\text { ein; BNP: brain nat }\end{array}$ & $\begin{array}{l}\text { ?; } P_{\mathrm{aO}_{2}}: \text { partial oxyc } \\
\text { xide; TLC: total li } \\
\text { etic peptide. }{ }^{*}: p<0\end{array}$ \\
\hline
\end{tabular}



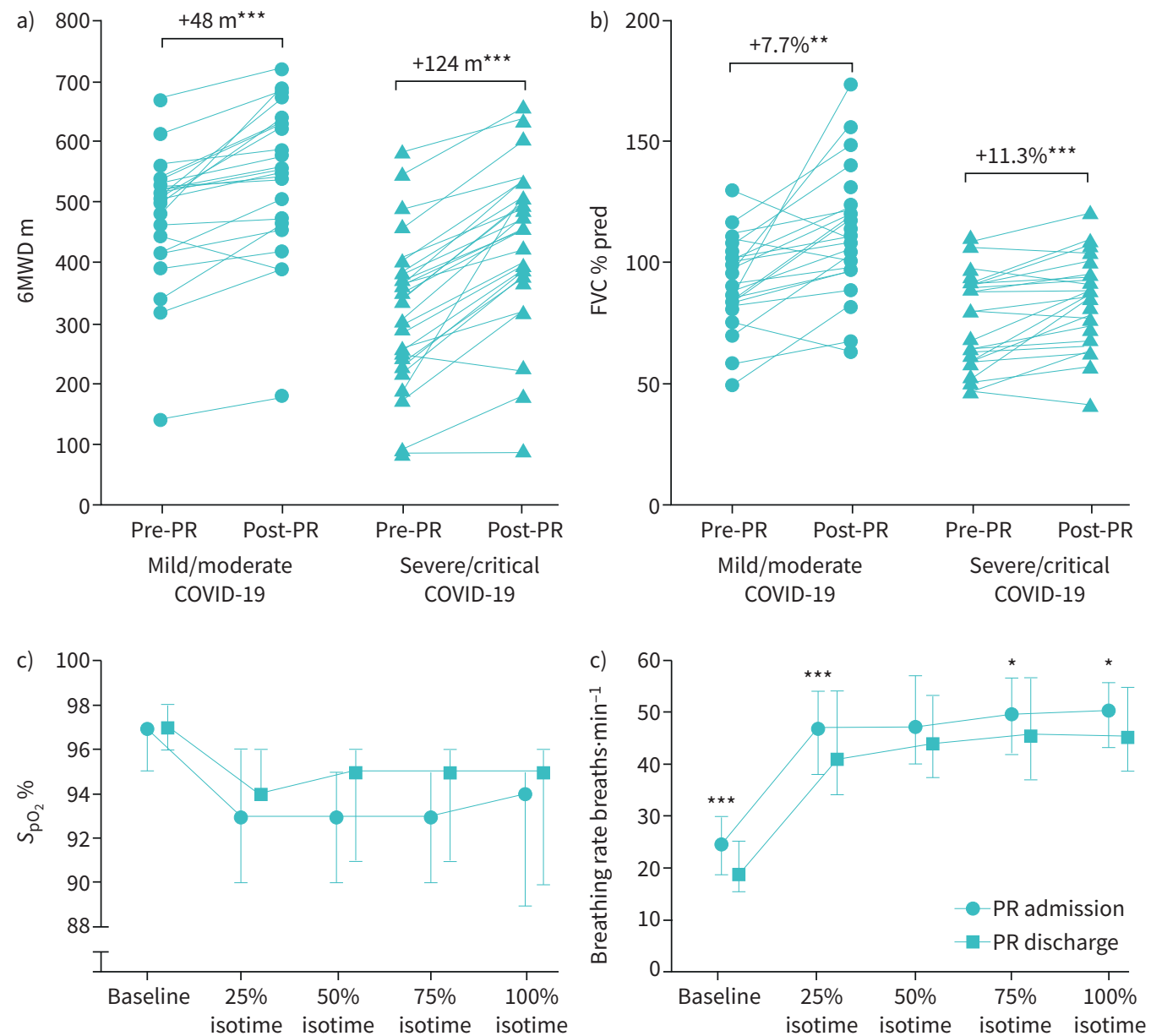

FIGURE 1 Changes in a) 6-min walk distance (6MWD) and b) forced vital capacity (FVC) pre- to post-comprehensive pulmonary rehabilitation (PR) in patients with mild/moderate $(n=24)$ and severe/critical $(n=26)$ coronavirus disease 2019 (COVID-19). c) Development of oxygen saturation $\left(\mathrm{S}_{\mathrm{pO}_{2}}\right)$ during endurance shuttle walk test (ESWT) from baseline to isotime in patients with severe to critical COVID-19 before and after PR. d) Development of breathing rate during ESWT from baseline to isotime in patients with severe to critical COVID-19 before and after PR. Data are presented as median and interquartile range. ${ }^{*}: p<0.05,{ }^{* *}: p<0.01$, $* * *: p<0.001$.

COVID-19. In line with our findings, they concluded that pulmonary rehabilitation following COVID-19 was effective to improve physical performance and subjective health status in these patients with severe disease.

In our study, patients with mild/moderate COVID-19 suffered from persistent physical impairments, as well patients with a severe/critical course of the disease. Despite significantly improving exercise performance, mild/moderate COVID-19 patients were still discharged with an impaired 6MWD (81\% pred). From experiences with SARS-CoV-1, it is known that the $6 \mathrm{MWD}$ could remain significantly lower compared to normal reference values even 1 year after the acute SARS-CoV-1 infection phase [29]. However, mild/moderate COVID-19 patients in our study improved 6MWD by $48 \mathrm{~m}$; clearly beyond the suggested MID of $30 \mathrm{~m}$ in patients with respiratory diseases ( $88 \%$ of patients exceeded this threshold) [15]. Even though a certain natural recovery effect cannot be ruled out, we suggest that these improvements seem to be related to the impact of pulmonary rehabilitation because patients reached this significant increase in 6MWD within 3 weeks of pulmonary rehabilitation, although their acute SARS-CoV-2 infection phase was 6 months prior. Furthermore, a study by DAHER et al. [30] in patients with severe COVID-19 has shown that exercise performance is still severely impaired 6 weeks after hospital discharge in patients who did not undergo pulmonary rehabilitation (median 6MWD $380 \mathrm{~m}$ ). This implies a slow natural recovery in severe COVID-19 patients following hospitalisation. Severe/critical COVID-19 patients in our study were able to increase 6MWD substantially from $344 \mathrm{~m}$ to $468 \mathrm{~m}$ (with $92 \%$ of patients exceeding the MID) at pulmonary rehabilitation discharge, which was 6 weeks after hospital discharge. A study by HUANG et al. [31] investigated 1733 hospitalised COVID-19 patients and found a median (IQR) 


\begin{tabular}{|c|c|c|c|c|}
\hline & Pre-PR & Post-PR & Change & p-value \\
\hline \multicolumn{5}{|l|}{ Fried frailty index } \\
\hline Non-frail & $0(0)$ & $3(12)$ & $-3(-12)$ & $<0.001$ \\
\hline Pre-frail & $8(31)$ & $16(62)$ & $8(31)$ & 0.060 \\
\hline Frail & $18(69)$ & $7(27)$ & $-11(-42)$ & 0.060 \\
\hline \multicolumn{5}{|l|}{ ESWT } \\
\hline Distance m & 430 (195-758) & 980 (390-1385) & $550(50-725)$ & $<0.001$ \\
\hline Time s & $460(217-625)$ & $1200(312-1200)$ & 740 (143-789) & 0.0001 \\
\hline Baseline $\mathrm{S}_{\mathrm{pO}_{2}} \%$ & 97 (95-97) & 97 (96-98) & $0(-1-2.5)$ & 0.021 \\
\hline Isotime $\mathrm{S}_{\mathrm{pO}_{2}} \%$ & $94(87-96)$ & $95(91-96)$ & $1(-1-3)$ & 0.053 \\
\hline $\mathrm{S}_{\mathrm{pO}_{2}}<90 \%$ & 9 (35) & 7 (27) & $-2(-8)$ & $<0.001$ \\
\hline Duration to ESWT $S_{\mathrm{pO}_{2}}<90 \% \mathrm{~S}$ & $50(18-122)$ & $163(32-276)$ & $113(13-262)$ & 0.028 \\
\hline $\mathrm{S}_{\mathrm{pO}_{2}}<85 \%$ & $5(19)$ & $1(4)$ & $-4(15)$ & $<0.001$ \\
\hline Duration to ESWT $\mathrm{S}_{\mathrm{pO}_{2}}<85 \% \mathrm{~s}$ & 89 (62-199) & 319 (319-319) & 230 (NA) & \\
\hline Baseline HR beats $\mathrm{min}^{-1}$ & $86(77-98)$ & 85 (75-95) & $-1(-8-4)$ & 0.35 \\
\hline Isotime HR beats $\cdot \min ^{-1}$ & $114(99-126)$ & $108(97-119)$ & $-6(-12-5)$ & 0.52 \\
\hline $\begin{array}{l}\text { Baseline breathing frequency } \\
\text { breaths } \cdot \min ^{-1}\end{array}$ & $24(18-30)$ & 19 (15-25) & $-5(-5-0)$ & 0.001 \\
\hline $\begin{array}{l}\text { Isotime breathing frequency } \\
\text { breaths } \cdot \mathrm{min}^{-1}\end{array}$ & $50(42-56)$ & $45(37-55)$ & $-5(-5-0)$ & 0.005 \\
\hline \multicolumn{5}{|l|}{ Muscle function } \\
\hline Handgrip strength kg & $25(18-35)$ & $30(20-39)$ & $5(3-7)$ & 0.002 \\
\hline Peak quadriceps strength \% pred & $78.4(48.6-98.1)$ & 99.6 (68.4-103.3) & $21.2(5.7-31.0)$ & 0.008 \\
\hline Five-rep STST s & $13.3(10.5-15.5)$ & $10.3(8.5-13.2)$ & $-3.0(-4.3-0.3)$ & 0.001 \\
\hline \multicolumn{5}{|l|}{$\begin{array}{l}\text { Psychological distress and (cognitive) } \\
\text { impairment }\end{array}$} \\
\hline PHQ-9 score & $7(4-12)$ & $4(2-10)$ & $-3(-4-0)$ & 0.002 \\
\hline $\begin{array}{l}\text { Signs of at least mild depression } \\
\text { according to } P H Q-9 \text { score } \geqslant 5\end{array}$ & $15(58)$ & 9 (35) & $-6(-23)$ & 0.031 \\
\hline GAD-7 score & $4(2-8)$ & $5(1-7)$ & $1(0-2)$ & 0.021 \\
\hline $\begin{array}{l}\text { Signs of at least mild anxiety } \\
\text { according to GAD-7 score } \geqslant 5\end{array}$ & $10(38)$ & 10 (38) & $0(0)$ & 1.00 \\
\hline MoCA score & $25(23-28)$ & $28(25-28)$ & $3(1-3)$ & 0.038 \\
\hline $\begin{array}{l}\text { Cognitive impairment according to } \\
\text { MoCA score }<26\end{array}$ & $12(46)$ & 6 (23) & $-6(-23)$ & 0.005 \\
\hline mMRC score & $2(2-2)$ & $2(1-2)$ & $0(-1-0)$ & 0.003 \\
\hline$m M R C$ score $\geqslant 1$ & 24 (92) & $23(88)$ & $-1(-4)$ & 1.00 \\
\hline $\mathrm{mMRC}$ score $\geqslant 2$ & 20 (77) & $14(54)$ & $-6(-23)$ & 0.031 \\
\hline
\end{tabular}

Data are presented as $\mathrm{n}(\%)$ or median (interquartile range), unless otherwise stated. Bold type represents statistical significance $(p<0.05)$. ESWT: endurance shuttle walk test; $S_{\mathrm{pO}_{2}}$ : oxygen saturation; HR: heart rate; STST: sit-to-stand test; PHQ-9: nine-item Patient Health Questionnaire (depression); GAD-7: Generalised Anxiety Disorder scale; MoCA: Montreal Cognitive Assessment; mMRC: modified Medical Research Council dyspnoea scale.

6MWD of $495 \mathrm{~m}(440-538 \mathrm{~m})$ at a 6-month follow-up after hospital discharge. COVID-19 patients in our study reached a comparable range of $6 \mathrm{MWD}$ at pulmonary rehabilitation discharge only 6 weeks after hospital discharge. It seems that the recovery of exercise performance can be accelerated when COVID-19 patients are referred to pulmonary rehabilitation after the acute phase of the disease. Despite this large improvement following pulmonary rehabilitation, patients with severe/critical COVID-19 still reached only $70.5 \%$ of their predicted 6MWD. This might be more related to the persisting impairments in respiratory capacity rather than to skeletal muscle weakness, because patients regained a normal level ( $99.6 \%$ pred) of their quadriceps strength at pulmonary rehabilitation discharge.

Until now, it is not clear whether COVID-19 will leave permanent lung damage and, if so, to what extent [12]. In our study, COVID-19 patients showed a restrictive lung function pattern, severely impaired gas exchange and an increased breathing rate during exertion.

Although lung function, gas exchange and breathing frequency improved significantly following pulmonary rehabilitation, patients were discharged with a persistent impaired respiratory function. From a 
2005 study in 97 SARS-CoV-1 survivors, it is known that $24 \%$ had persistent reduced lung diffusion compared to healthy control subjects even at a 1-year follow-up [29]. Furthermore, 28-62\% of SARS-CoV-1 survivors exhibited decreased lung function and increased lung fibrosis [32]. Currently, there is some evidence that suggests that the development of a fibrotic lung disease as an outcome of COVID-19 is a serious concern $[33,34]$. Since our study was not randomised and does not contain a COVID-19 control group without pulmonary rehabilitation we would like to draw an indirect comparison by using a group of idiopathic pulmonary fibrosis (IPF) patients from a former study of our working group where the same outcome measures were assessed [35]. This IPF comparison group did not undergo pulmonary rehabilitation and had a comparable impairment in lung function (supplementary tables S1 and S2). However, at pulmonary rehabilitation admission, COVID-19 patients with a severe/critical course showed a significantly lower 6MWD and mental health summary score compared to IPF patients. COVID-19 patients were able to improve all mentioned outcomes following pulmonary rehabilitation, whereas IPF patients in our non-pulmonary rehabilitation comparison group did not change in any of these outcomes at a 2-months follow-up assessment. In the lack of a COVID-19 non-pulmonary rehabilitation control group, this comparison to non-pulmonary rehabilitation IPF patients may give a further clue that pulmonary rehabilitation in COVID-19 is beneficial beyond the natural recovery. However, although COVID-19 patients had a restrictive lung function pattern, this comparison must be interpreted with caution, since COVID-19 causes acute damage, whereas IPF is a chronic progressing disease.

Approximately $75 \%$ of hospitalised COVID-19 patients show abnormal patient-reported outcome measures 3 months after symptom onset, with $33 \%$ of patients reporting at least moderate impairments in major dimensions of quality of life [36]. Consistently, patients in our study showed impairments in physical and mental quality of life. Notably, these patients in our study with severe/critical COVID-19 course experienced significantly lower mental quality of life than a comparison group of IPF patients (supplementary table S1). Within our subsample of severe/critical COVID-19 patients, 58\% showed at least mild depression and $38 \%$ at least mild anxiety symptoms. Notably, this group showed much more psychological distress than comparable cohorts of severe/critical COVID-19 3 months after symptom onset (24\% mood impairment) [36] or 6 months after symptom onset (32\% anxiety or depression) [31]. We found that mental quality of life and depression improved significantly in patients with severe/critical COVID-19 (although 35\% of patients were still reporting at least mild depression symptoms after pulmonary rehabilitation). We acknowledge that these effects could also be interpreted as spontaneous remission. However, the onset of symptoms in our patients was 2 months prior to the pulmonary rehabilitation programme. Therefore, we attribute these improvements mainly to the impact of the pulmonary rehabilitation programme, which also included specific interventions focusing on disease management as well as on coping with COVID-19 and its sequelae.

Interestingly, pulmonary rehabilitation was not associated with a change in the number of patients reporting at least mild anxiety symptoms. However, patients' anxiety scores increased slightly but significantly. Potentially, patients only began during pulmonary rehabilitation to reflect on daily life challenges as a result of their COVID-19 disease. Specifically, the increasing focus on day-to-day functioning along with patients' awareness of their persistent impairments (e.g. in cognitive function) may have resulted in higher anxiety scores. Of course, this finding needs replication before further interpretation. However, a potential area for future research could be that pulmonary rehabilitation and possible interventions that take place after pulmonary rehabilitation, should monitor and focus on patients' disease-specific and future related anxieties and help, to cope with their ongoing impairments after pulmonary rehabilitation.

The most relevant limitation of our study is the absence of a randomised COVID-19 control group, which was not possible due to ethical issues. However, the known COVID-19 sequelae from other studies without pulmonary rehabilitation, the comparison to a non-pulmonary rehabilitation group of IPF patients, and the large gains that mild/moderate COVID-19 patients reached during 3 weeks of pulmonary rehabilitation (even 6 months after their acute SARS-CoV-2 infection) suggest, that these benefits are more related to pulmonary rehabilitation rather than to only a natural convalescence. A second limitation of our study might be a specific selection bias, because COVID-19 patients mainly with a focus on lung disease were referred to our pulmonary rehabilitation programme. However, it is known that there are COVID-19 patients in which neural, cardiac, renal, gastrointestinal or coagulative disorders dominate [37]. This limits the generalisability of our findings. A third limitation might be that patients did not perform a practice 6-min walk test.

A strength of our study is the inclusion of patients with the full spectrum of disease severity and the collection of a comprehensive dataset that provides an important insight into the benefits of pulmonary rehabilitation in COVID-19 patients. 


\section{Conclusion}

Our study shows that pulmonary rehabilitation is effective, feasible and safe to improve exercise performance, lung function and quality of life in patients with persistent impairments due to a mild to critical course of COVID-19. Further randomised controlled trials including follow-up assessments are needed to assess long-term benefits of pulmonary rehabilitation.

Acknowledgement: We thank Daniel Felde (University of Giessen, Germany) for supporting data collection.

Author contributions: R. Gloeckl, D. Leitl, T. Schneeberger, I. Jarosch, K. Kenn and A.R. Koczulla designed the study. R. Gloeckl, D. Leitl, T. Schneeberger, I. Jarosch and A.R. Koczulla were involved in recruiting patients and collecting the data. D. Leitl and R. Gloeckl verified the underlying data. R. Gloeckl and C. Nell performed statistical analyses. R. Gloeckl and D. Leitl drafted the manuscript. R. Gloeckl, D. Leitl, T. Schneeberger, I. Jarosch, C. Nell, N. Stenzel, C.F. Vogelmeier, K. Kenn and A.R. Koczulla provided scientific discussion and revised the initial draft. All authors had full access to all the data in the study and accept responsibility to submit for publication. All authors approved the final version of the manuscript.

Conflict of interest: None declared.

Support statement: This study was funded by own resources of the study centre (Schoen Klinik Berchtesgadener Land, Schoenau am Koenigssee, Germany) and did not receive any external funding.

\section{References}

1 The Novel Coronavirus Pneumonia Emergency Response Epidemiology Team. The epidemiological characteristics of an outbreak of 2019 novel coronavirus diseases (COVID-19) - China, 2020. China CDC Weekly 2020; 2: $113-122$.

2 World Health Organization. Clinical Management of COVID-19. May 27, 2020. Available from: www.who.int/ publications/i/item/clinical-management-of-covid-19

3 Huang C, Huang L, Wang Y, et al. 6-month consequences of COVID-19 in patients discharged from hospital: a cohort study. Lancet 2021; 397: 220-232.

4 Zhou F, Yu T, Du R, et al. Clinical course and risk factors for mortality of adult inpatients with COVID-19 in Wuhan, China: a retrospective cohort study. Lancet 2020; 395: 1054-1062.

5 Halpin SJ, McIvor C, Whyatt G, et al. Postdischarge symptoms and rehabilitation needs in survivors of COVID-19 infection: a cross-sectional evaluation. I Med Virol 2021; 93: 1013-1022.

6 Carfi A, Bernabei R, Landi F. Persistent symptoms in patients after acute COVID-19. JAMA 2020; 324: 603-605.

7 Goërtz YMJ, Van Herck M, Delbressine JM, et al. Persistent symptoms 3 months after a SARS-CoV-2 infection: the post-COVID-19 syndrome? ERJ Open Res 2020; 6: 00542-2020.

8 Wang C, Pan R, Wan X, et al. Immediate psychological responses and associated factors during the initial stage of the 2019 coronavirus disease (COVID-19) epidemic among the general population in China. Int J Environ Res Public Health 2020; 17: 1729.

9 National Institute for Health and Care Excellence. COVID-19 Rapid Guideline: Managing the Long-Term Effects of COVID-19. NICE guideline [NG188]. 18 December 2020. www.nice.org.uk/guidance/ng188

10 Greenhalgh T, Knight M, A'Court C, et al. Management of post-acute covid-19 in primary care. BMJ 2020; 370 : m3026.

11 Spruit MA, Holland AE, Singh SJ, et al. COVID-19: interim guidance on rehabilitation in the hospital and post-hospital phase from a European Respiratory Society and American Thoracic Society-coordinated International Task Force. Eur Respir J 2020; 56: 2002197.

12 Polastri M, Nava S, Clini E, et al. COVID-19 and pulmonary rehabilitation: preparing for phase three. Eur Respir J 2020; 55: 2001822

13 Vitacca M, Lazzeri M, Guffanti E, et al. An Italian consensus on pulmonary rehabilitation in COVID-19 patients recovering from acute respiratory failure: results of a Delphi process. Monaldi Arch Chest Dis 2020; 90: https:// doi.org/10.4081/monaldi.2020.1444.

14 Carda S, Invernizzi M, Bavikatte G, et al. The role of physical and rehabilitation medicine in the COVID-19 pandemic: the clinician's view. Ann Phys Rehabil Med 2020; 63: 554-556.

15 Holland AE, Spruit MA, Troosters T, et al. An official European Respiratory Society/American Thoracic Society technical standard: field walking tests in chronic respiratory disease. Eur Respir J 2014; 44: 1428-1446.

16 Maltais F, Decramer M, Casaburi R, et al. An official American Thoracic Society/European Respiratory Society statement: update on limb muscle dysfunction in chronic obstructive pulmonary disease. Am J Respir Crit Care Med 2014; 189: e15-e62.

17 Jones SE, Kon SS, Canavan JL, et al. The five-repetition sit-to-stand test as a functional outcome measure in COPD. Thorax 2013; 68: 1015-1020.

18 Fried LP, Tangen CM, Walston J, et al. Frailty in older adults: evidence for a phenotype. J Gerontol A Biol Sci Med Sci 2001; 56: M146-M156.

19 Bestall JC, Paul EA, Garrod R, et al. Usefulness of the Medical Research Council (MRC) dyspnoea scale as a measure of disability in patients with chronic obstructive pulmonary disease. Thorax 1999; 54: 581-586.

20 Löwe B, Decker O, Müller S, et al. Validation and standardization of the Generalized Anxiety Disorder Screener (GAD-7) in the general population. Med Care 2008; 46: 266-274.

21 Kroenke K, Spitzer RL, Williams JB. The PHQ-9: validity of a brief depression severity measure. J Gen Intern Med 2001; 16: 606-613.

22 Ihle-Hansen H, Vigen T, Berge T, et al. Montreal Cognitive Assessment in a 63- to 65-year-old Norwegian cohort from the general population: data from the Akershus Cardiac Examination 1950 study. Dement Geriatr Cogn Dis Extra 2017; 7: 318-327.

23 Negrini F, De Sire A, Andrenelli E, et al. Rehabilitation and COVID-19: a rapid living systematic review 2020 by Cochrane Rehabilitation Field. Update as of October 31st, 2020. Eur J Phys Rehabil Med 2021; 57: 166-170. 
24 Ferraro F, Calafiore D, Dambruoso F, et al. COVID-19 related fatigue: which role for rehabilitation in post-COVID-19 patients? A case series. J Med Virol 2021; 93: 1869-1899.

25 Wootton SL, King M, Alison JA, et al. COVID-19 rehabilitation delivered via a telehealth pulmonary rehabilitation model: a case series. Respirol Case Rep 2020; 8: e00669.

26 Liu K, Zhang W, Yang Y, et al. Respiratory rehabilitation in elderly patients with COVID-19: a randomised controlled study. Complement Ther Clin Pract 2020; 39: 101166.

27 Spruit MA, Singh SJ, Garvey C, et al. An official American Thoracic Society/European Respiratory Society statement: key concepts and advances in pulmonary rehabilitation. Am J Respir Crit Care Med 2013; 188: e13-e64.

28 Hermann M, Pekacka-Egli AM, Witassek F, et al. Feasibility and efficacy of cardiopulmonary rehabilitation after COVID-19. Am J Phys Med Rehabil 2020; 99: 865-869.

29 Hui DS, Wong KT, Ko FW, et al. The 1-year impact of severe acute respiratory syndrome on pulmonary function, exercise capacity, and quality of life in a cohort of survivors. Chest 2005; 128: 2247-2261.

30 Daher A, Balfanz P, Cornelissen C, et al. Follow up of patients with severe coronavirus disease 2019 (COVID-19): pulmonary and extrapulmonary disease sequelae. Respir Med 2020; 174: 106197.

31 Huang C, Huang L, Wang Y, et al. 6-month consequences of COVID-19 in patients discharged from hospital: a cohort study. Lancet 2021; 397: 220-232.

32 McDonald LT. Healing after COVID-19: are survivors at risk for development of pulmonary fibrosis? Am J Physiol Lung Cell Mol Physiol 2021; 320: L257-L265.

33 Spagnolo P, Balestro E, Aliberti S, et al. Pulmonary fibrosis secondary to COVID-19: a call to arms? Lancet Respir Med 2020; 8: 750-752

34 Guler SA, Ebner L, Beigelman C, et al. Pulmonary function and radiological features four months after COVID-19: first results from the national prospective observational Swiss COVID-19 lung study. Eur Respir J 2021; 57: 2003690.

35 Jarosch I, Schneeberger T, Gloeckl R, et al. Short-term effects of comprehensive pulmonary rehabilitation and its maintenance in patients with idiopathic pulmonary fibrosis: a randomised controlled trial. J Clin Med 2020; 9 ; 1567.

36 Wong AW, Shah AS, Johnston JC, et al. Patient-reported outcome measures after COVID-19: a prospective cohort study. Eur Respir J 2020; 56: 2003276.

37 Gavriatopoulou M, Korompoki E, Fotiou D, et al. Organ-specific manifestations of COVID-19 infection. Clin Exp Med 2020; 20: 493-506. 